\title{
'Yan Xia': A Novel Cultivar of Xanthoceras sorbifolium Bunge with Ornamental Value
}

\author{
Yuxin Chen \\ Key Laboratory for Silviculture and Conservation, Ministry of Education, \\ Beijing Forestry University, No. 35 Qinghua East Road, Haidian District, \\ Beijing 100083, China; and Beijing Laboratory of Urban and Rural \\ Ecological Environment, No. 35 Qinghua East Road, Haidian District, \\ Beijing 100083, China

\section{Zishuo Zhang, Kexin Wang, Lijin Ou, and Yan Ao \\ Key Laboratory for Silviculture and Conservation, Ministry of Education, Beijing Forestry University, No. 35 Qinghua East Road, Haidian District, Beijing 100083, China}

Additional index words. cultivation technology, economic value, plant breeding, urban afforestation, yellow-horn

Yellow-horn (Xanthoceras sorbifolium Bunge), a valuable plant native to China, is a member of the family Sapindaceae. It is mainly distributed in North China, with a cultivation history of more than 1000 years (Ma et al., 2020). The species can be a tree or shrub, depending on the site conditions. Most trees are tall arbors with a round or spreading crown. Yellow-horn is characterized by a long period of blooming and a high number of flowers. The seed oil is highly valuable for cooking, and as a medicine and biofuel (Ruan et al., 2016; Shen et al., 2019). Yellow-horn is considered an ideal tree species with ecological, economic, and ornamental value. During recent years, yellow-horn has garnered attention and has been widely planted (Wang et al., 2019). Thirty-five varieties of yellowhorn have been certified by the National Forestry and Grassland Administration. 'Yan Xia' was successfully cultivated in July 2016. It can be grown in North China because of its cold- and drought-resistant nature. 'Yan $X i a$ ' has a greater number of petals than other varieties of yellow-horn. The color of petals changes throughout the blooming period. 'Yan Xia' is taller and has a longer flores-

Received for publication 28 Oct. 2020. Accepted for publication 28 Dec. 2020.

Published online 4 March 2021

This research was funded by the National Natural Science Foundation of China (no. 32071738) and the Fundamental Research Funds for the Central Universities (2015ZCQ-LX-02).

We thank the reviewers and editors for their thoughtful comments and suggestions on the manuscript. We are grateful to Jinfeng Liu and Xingjie Zhang for providing the seedlings. We also thank Editage for providing language editorial assistance. Y.A. is the corresponding author. E-mail: aoyan316@ 163.com.

This is an open access article distributed under the CC BY-NC-ND license (https://creativecommons. org/licenses/by-nc-nd/4.0/). surviving grafted plantlets were collected, and second-generation grafted plantlets were cultivated. A 90\% survival rate was attained in consecutive grafting experiments. All grafted plantlets flowered in 2016. 'Yan Xia' displayed the same traits as the maternal parent, indicating the traits are genetically stable (Ao, 2016a).

\section{Plant Characteristics}

'Yan Xia' is expected to be propagated in North China. It can reach a mature height of 2 to $7 \mathrm{~m}$. It has racemose inflorescences, and the flowers bloom before or at the same time as leaf sprouting (Fig. 1A). Normally, each flower has $\approx 20$ petals. The petals are twisted and curled, and are of various sizes. The petals near the outer edges of flowers are wide and large; those near the center are narrow and small. The pistil, stamens, and golden hornlike appendages mutate into petals, making 'Yan Xia' a nonfruiting cultivar (Fig. 2A) (Ao, 2016b). The sacs on the inner small petals are derived from yellow anthers filled with pollen. The color of the petals changes gradually as the flowers mature. During the early blossom period, the petals are yellow at their base and white above. The base turns purplish red during the full-bloom stage (Fig. 2B). The cultivar bears no fruit, and this helps the plant to conserve nutrients. Normally, 'Yan Xia' grows taller, with a wider crown and longer blooming period than other varieties of yellow-horn. In Chengde City, Hebei Province, 'Yan Xia' begins to blossom in early May, which usually lasts for $25 \mathrm{~d}$. Consequently, 'Yan Xia' is an attractive choice for urban afforestation in northern China.

The leaves of 'Yan Xia' are obovate and slightly curled, with gradually pointed apices and cuneate bases. The imparipinnate leaves are serrated, and are dark green on the adaxial side and light green on the abaxial side (Fig. 1B).

Table 1 shows the distinctiveness of 'Yan Xia' by comparing it with 'Sen Miao', a common variety of yellow-horn. 

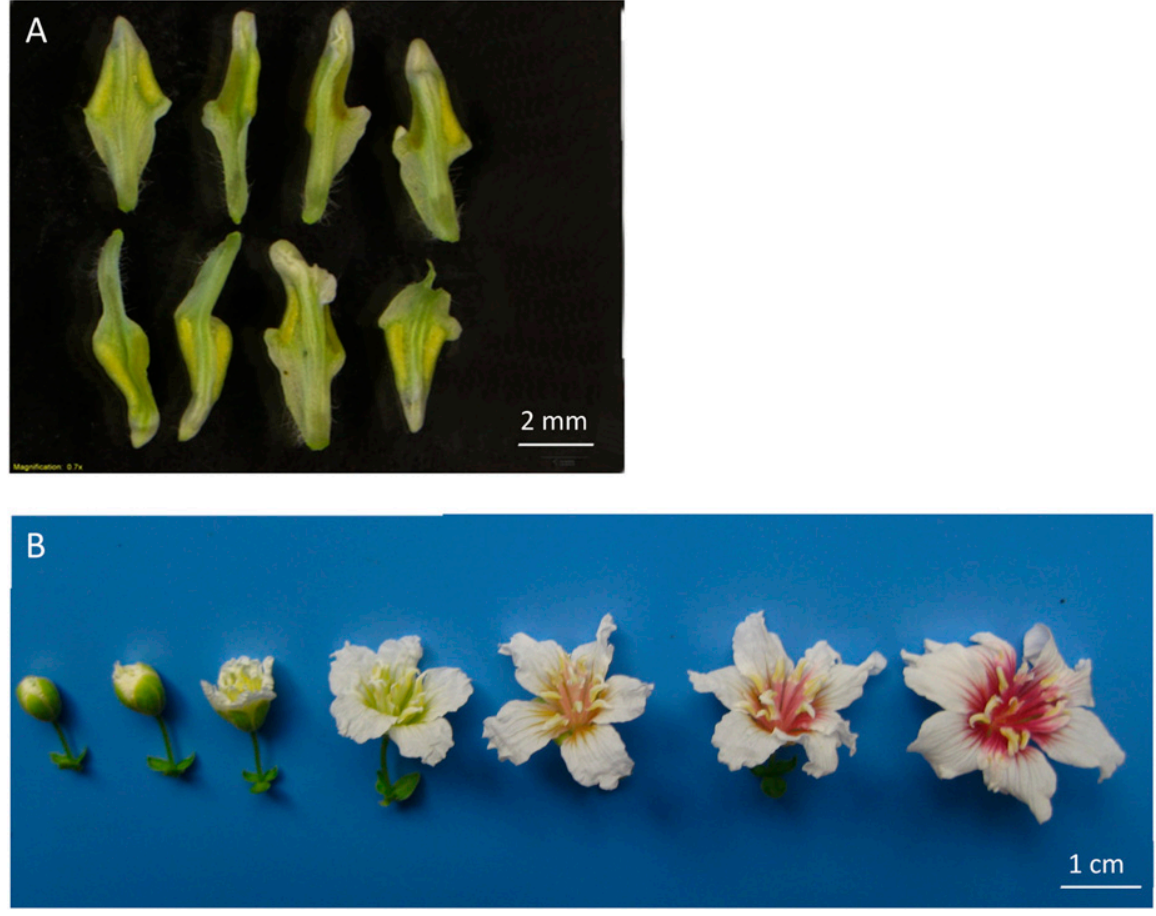

Fig. 2. Morphological characters of 'Yan Xia' under a microscope: (A) petaloid stamens and (B) flowers in different blossom periods.

Table 1. Different characteristics of 'Yan Xia' and 'Sen Miao'.

\begin{tabular}{lll}
\hline Characteristic & \multicolumn{1}{c}{ Yan Xia } & \multicolumn{1}{c}{ Sen Miao } \\
\hline $\begin{array}{l}\text { Petal number } \\
\text { Petal shape }\end{array}$ & $\begin{array}{l}\text { Rolled up and crowded irregularly; petals } \\
\text { are wide and large near the outer edge and } \\
\text { narrow and small at the center }\end{array}$ & Explanate \\
Pistil & $\begin{array}{l}\text { Petalody } \\
\text { Mutate into small petals in the center of } \\
\text { Stamen }\end{array}$ & $\begin{array}{l}\text { Ovary coated with gray hairs } \\
\text { the corolla with long sacs filled with pollen }\end{array}$ \\
Fruit & Unfruitful & Fruitful, spherical capsule \\
\hline
\end{tabular}

\section{Dissemination of the Cultivar}

'Yan Xia' shows strong resistance to drought and cold. It prefers sunshine, dry terrain, and thick, neutral to slightly alkaline soil with good drainage. Scarification is of importance for seedlings to avoid root rot. The cultivar is appropriate for propagation in China from Liaoning in the east to Xinjiang in the west, and from Inner Mongolia in the north to Henan in the south. It is distributed between latitude $28^{\circ} 34^{\prime}-47^{\circ} 20^{\prime} \mathrm{N}$ and longitude $73^{\circ} 20^{\prime}-120^{\circ} 25^{\prime} \mathrm{E}$, and is mainly restricted to the continental and monsoon climate zones. The average annual tempera- for transplanting large plantlets. It is important to protect the roots during transplantation. Application of sufficient amounts of organic base fertilizers is recommended. Topdressing is of importance; it should be applied in early spring before sprouting (nitrogen fertilizer), during florescence to promote bud initiation and flower opening (nitrogen and phosphate fertilizers), and in autumn before October (phosphate and potash fertilizers). The fertilization rate depends on soil fertility and plant growth.

Cultivation and weeding should be conducted two to three times during the growing season. Irrigation is necessary during drought, and before flowering and soil freezing. During the rainy season, drainage is necessary to avoid root rot.

Pruning and trimming should be conducted ideally during the dormancy period. The overcrowded branches, overlapping branches, crossing branches, thin branches, and branches infected with pests and diseases should be pruned.

\section{Availability}

Small samples of 'Yan Xia' are available commercially from Beijing Forestry University. Requests for cuttings for research purposes may be addressed to Dr. Yan Ao (e-mail: aoyan316@163.com).

\section{Literature Cited}

Ao, Y. 2016a. Characterization and comparison of flower bud microRNAs from yellow-horn species. Genet. Mol. Res. 15(4):gmr.15048899, doi: $10.4238 / \mathrm{gmr} .15048899$.

Ao, Y. 2016b. Comparison of floral ontogeny between wild-type yellow-horn (Xanthoceras sorbifolia Bunge) and its double-flowered mutant. Bangladesh J. Bot. 45(2):367-375.

Ma, Y.X., Q.X. Bi, G.T. Li, X.J. Liu, G.H. Fu, Y. Zhao, and L.B. Wang. 2020. Provenance variations in kernel oil content, fatty acid profile and biodiesel properties of Xanthoceras sorbifolium Bunge in northern China. Ind. Crops Prod. 151, doi: 10.1016/j.indcrop.2020.112487.

Ruan, C.J., R. Yan, B.X. Wang, S. Mopper, W.K. Guan, and J. Zhang. 2016. The importance of yellow horn (Xanthoceras sorbifolia) for restoration of arid habitats and production of bioactive seed oils. Ecol. Eng. 99:504-512, doi: 10.1016/j.ecoleng.2016.11.073.

Shen, Z., K.Q. Zhang, Y. Ao, L.Y. Ma, and J. Duan 2019. Evaluation of biodiesel from Xanthoceras sorbifolia Bunge seed kernel oil from 13 areas in China. J. For. Res. 30(3):869-877, doi: 10.1007/s11676-018-0683-9.

Wang, X., Y.Q. Zheng, S.C. Su, and Y. Ao. 2019 Discovery and profiling of microRNAs at the critical period of sex differentiation in Xanthoceras sorbifolium Bunge. Forests 10(12):1141, doi: 10.3390/f10121141. 